\title{
Persistent arthralgia, vomiting and hypercalcemia as the initial manifestations of hyperthyroidism: A case report
}

\author{
JINGFANG LIU, XULEI TANG, JIANGUO CHENG, XIAOMEI YANG and YAN WANG \\ Department of Endocrinology, The First Hospital of Lanzhou University, Lanzhou, Gansu 730000, P.R. China
}

Received April 2, 2016; Accepted June 21, 2016

DOI: $10.3892 / \mathrm{mco} .2017 .1127$

\begin{abstract}
A 53-year-old woman presented with persistent edema and pain of the metacarpophalangeal and proximal interphalangeal joints and the wrist, knee and ankle joints, with more recent intermittent nausea and vomiting. Treatment for rheumatoid arthritis and osteoarthritis was ineffective. No clinical manifestations typical of hyperthyroidism were observed. The results of the thyroid function tests were as follows: Thyroid-stimulating hormone, $0.003 \mu \mathrm{IU} / \mathrm{ml}$; triiodothyronine $\left(\mathrm{T}_{3}\right), 4.44 \mathrm{ng} / \mathrm{ml}$; , thyroxine $\left(\mathrm{T}_{4}\right)>30 \mu \mathrm{g} / \mathrm{dl}$; free $\mathrm{T}_{3}, 14.03 \mathrm{pg} / \mathrm{ml}$; and free $\mathrm{T}_{4}, 8.84 \mathrm{ng} / \mathrm{dl}$. The laboratory tests revealed an elevated serum calcium level (2.96 mmol/l); moderate hypophosphatemia $(0.84 \mathrm{mmol} / 1)$; significantly reduced serum intact parathyroid hormone $(4.8 \mathrm{pg} / \mathrm{ml})$; normal 25-hydroxy vitamin D (52.13 nmol/l) and bone-specific alkaline phosphatase $(22.1 \mathrm{ng} / \mathrm{ml})$; and elevated osteocalcin $(128.8 \mathrm{ng} / \mathrm{ml})$. X-ray and quantitative ultrasound examinations revealed extensive osteoporosis of the hands, skull, knees and pelvis, with a bone mineral density of $0.254 \mathrm{~g} / \mathrm{cm}^{2}$ (T-score, -3.2). Anti-thyroid therapy (methimazole, $30 \mathrm{mg} / \mathrm{day}$; salmon calcitonin, $50 \mathrm{IU} /$ day; and alendronate, $70 \mathrm{mg} /$ week) was initiated. After 2 weeks, the serum calcium and phosphate levels were normalized (2.44 and $1.19 \mathrm{mmol} / \mathrm{l}$, respectively) and calcitonin was discontinued. After 3 months, the patient had no nausea, vomiting or joint pain, and her appetite was normal, with a weight gain of $\sim 10 \mathrm{~kg}$. Euthyroidism was achieved and the serum calcium and phosphate levels were normalized (2.31 and $1.12 \mathrm{mmol} / \mathrm{l}$, respectively) and maintained for 6 months, by which time the osteocalcin level had diminished $(80.40 \mathrm{ng} / \mathrm{ml})$. This rare case of arthralgia, hypercalcemia and extensive osteoporosis as the first manifestations of hyperthyroidism suggests that, even without typical symptoms, hyperthyroidism should be considered in the differential diagnosis of patients with persistent arthralgia.
\end{abstract}

Correspondence to: Dr Jingfang Liu, Department of Endocrinology, The First Hospital of Lanzhou University, 1 Donggang West Road, Lanzhou, Gansu 730000, P.R. China E-mail: 1jf824168@126.com

Key words: hyperthyroidism, hypercalcemia, osteoporosis, arthralgia

\section{Introduction}

Hyperthyroidism is associated with accelerated bone remodeling, reduced bone density and osteoporosis (1). These changes in bone metabolism are associated with a negative calcium balance, hypercalciuria and, rarely, hypercalcemia, which occurs in hyperthyroidism alone or due to concurrent hyperparathyroidism. Asymptomatic serum calcium elevation has been documented in $\leq 20 \%$ of patients with hyperthyroidism and is associated with increased bone resorption (2). Symptomatic hypercalcemia has been reported as an uncommon occurrence in hyperthyroidism, with calcium levels rarely exceeding $12 \mathrm{mg} / \mathrm{dl}$ (3). We herein report the case of a patient with hyperthyroidism, who presented with persistent arthralgia, hypercalcemia and vomiting as the initial manifestations.

\section{Case presentation}

A 53-year-old post-menopausal woman (menopause at 46 years of age) presented with a 6-year history of joint pain and edema, with intermittent nausea and vomiting over the past 6 months. Initially, the patient had experienced edema and pain of the metacarpophalangeal and proximal interphalangeal joints, and the wrist, knee and ankle joints, accompanied by periods of stiffness in the morning, lasting $20 \mathrm{~min}$. The patient was diagnosed with rheumatoid arthritis and was prescribed appropriate medication at a local hospital; however, the symptoms did not subside with the treatment. Three years later, the patient was diagnosed with osteoarthritis by the orthopedist in our hospital and treated with topical diclofenac (Voltaren) and intra-articular injection of betamethasone, without significant benefit. The patient's general condition gradually deteriorated, with intermittent nausea and vomiting developing over the previous 6 months; she was referred to another hospital, where the diagnosis of rheumatoid arthritis was again considered. Prednisone ( $15 \mathrm{mg}$ /day) was initiated and after $\sim 10$ days, the patient was discharged. Prednisone treatment was continued at a lower dosage ( $5 \mathrm{mg}$ /day); however, the symptoms of nausea and vomiting reappeared. After 1 month, thyroid function tests showed a thyroid-stimulating hormone (TSH) level of $0.001 \mu \mathrm{IU} / \mathrm{ml}$ (normal range, 0.55-4.78 $\mu \mathrm{IU} / \mathrm{ml}$ ); triiodothyronine $\left(\mathrm{T}_{3}\right) 6.07 \mathrm{ng} / \mathrm{ml}$ (normal range, 0.60-1.81 ng/ml) and thyroxine $\left(\mathrm{T}_{4}\right) 30 \mu \mathrm{g} / \mathrm{dl}$ (normal range, 4.50-10.90 $\mu \mathrm{g} / \mathrm{dl}$ ), consistent with a diagnosis of hyperthyroidism. Therapy with 

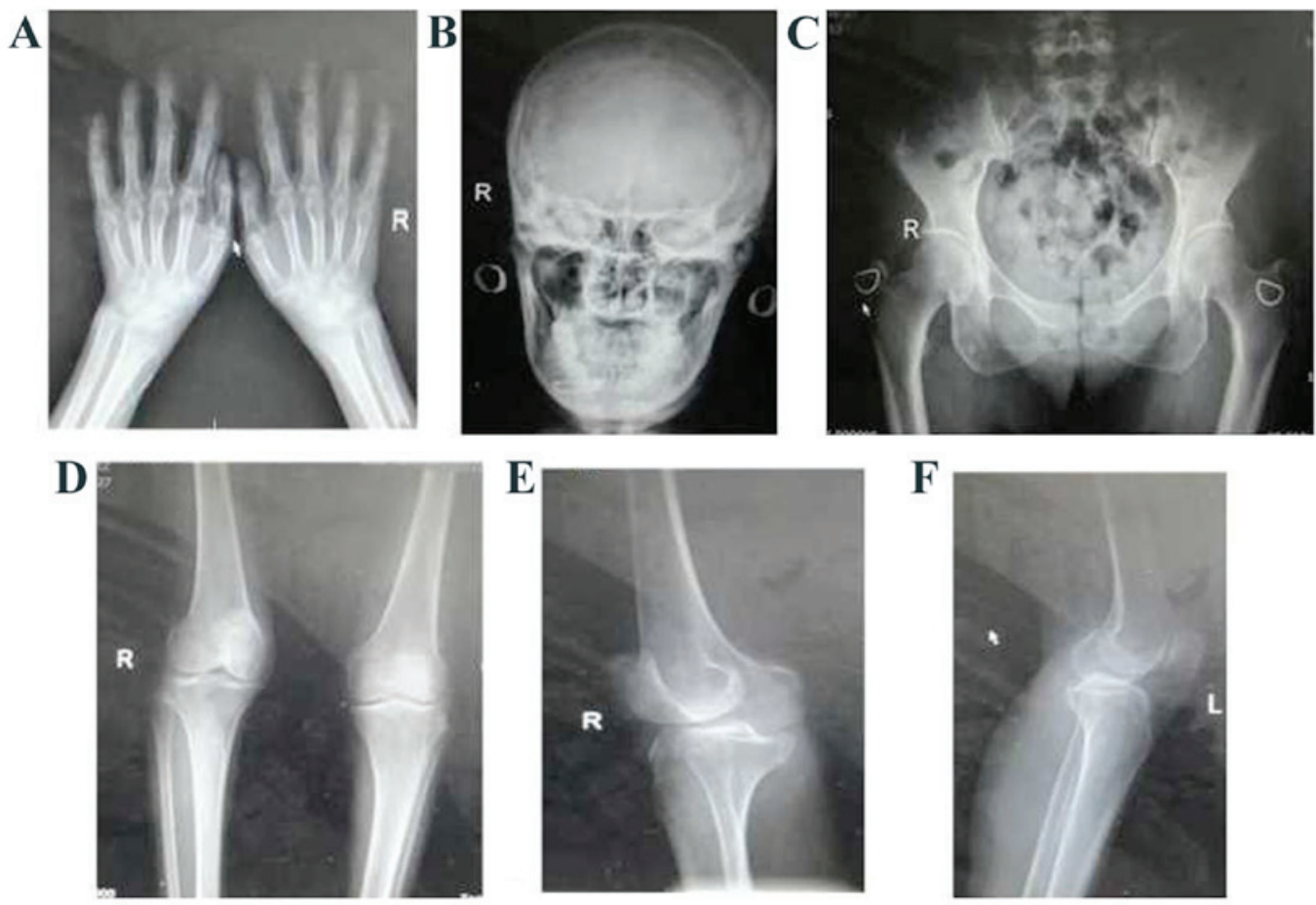

Figure 1. X-ray images of the (A) joints of the hand; (B) skull; and (C) pelvis; (D) anteroposterior image of both knees; (E) lateral image of the right knee; and (F) lateral image of the left knee, showing extensive osteoporotic changes.

methimazole (10 $\mathrm{mg}$ three times a day) and propranolol (10 $\mathrm{mg}$ three times a day) was initiated. However, the symptoms of nausea and vomiting persisted and after 2 weeks the patient was referred to our hospital.

At first appearance, the patient looked wasted and chronically ill. The findings of the physical examination at the time of admission were as follows: Temperature, $36.8^{\circ} \mathrm{C}$; pulse, 100 beats/min; respiration, 20 breaths/min; and blood pressure, $120 / 80 \mathrm{mmHg}$. No ophthalmopathy, lymphadenopathy or jaundice were observed, although there was mild anemia. The thyroid gland was enlarged, without an audible bruit. The heart and lungs were normal. No fine finger tremor was observed, the extremities appeared normal and the neurological examination was negative.

The laboratory tests revealed a TSH level of $0.003 \mu \mathrm{IU} / \mathrm{ml}$, $\mathrm{a} \mathrm{T}_{3}$ level of $4.44 \mathrm{ng} / \mathrm{ml}, \mathrm{a} \mathrm{T}_{4}$ level of $>30 \mu \mathrm{g} / \mathrm{dl}$, a free $\mathrm{T}_{3}$ level of $14.03 \mathrm{pg} / \mathrm{ml}$ (normal range, $2.3-4.2 \mathrm{pg} / \mathrm{ml}$ ), and a free $\mathrm{T}_{4}$ level of $8.84 \mathrm{ng} / \mathrm{dl}$ (normal range, $0.89-1.76 \mathrm{ng} / \mathrm{dl}$ ). The TSH receptor antibodies, thyroid peroxidase antibodies and thyroglobulin antibodies were negative. The hemoglobin level was $90 \mathrm{~g} / 1$ and the white blood cell count was $5.54 \times 10^{9} / 1$, with a normal differential count. The liver and renal function tests were normal. The serum calcium was $2.96 \mathrm{mmol} / \mathrm{l}$ (normal range, 2.10-2.80 mmol/l), with a normal albumin level and a serum phosphate level of $0.84 \mathrm{mmol} / 1$ (normal, 0.97-1.60 mmol/l). The serum intact parathyroid hormone level was $4.8 \mathrm{pg} / \mathrm{ml}$ (normal range, $14-72 \mathrm{pg} / \mathrm{ml}$ ), the 25 -hydroxy vitamin $\mathrm{D}$ was $52.13 \mathrm{nmol} / 1$ (normal range, 47.7-144 nmol/1), osteocalcin was $128.8 \mathrm{ng} / \mathrm{ml}$ (normal range, 12.8-55 ng/ml) and bonespecific alkaline phosphatase was $22.1 \mathrm{ng} / \mathrm{ml}$ (normal range, 7.3-22.4 ng/ml). The urine calcium was $11.29 \mathrm{mmol} / 24 \mathrm{~h}$ (normal range, $2.5-7.5 \mathrm{mmol} / 24 \mathrm{~h}$ ), and the urine phosphate was $9.55 \mathrm{mmol} / 24 \mathrm{~h}$ (normal range, $23-48 \mathrm{mmol} / 24 \mathrm{~h}$ ). The serum immunoglobulin (Ig) A, IgG and IgM levels were normal. The urine was negative for Bence-Jones protein. The erythrocyte sedimentation rate, components 3, 4, and rheumatoid factor were normal. Parathyroid scintigraphy revealed no abnormalities. X-ray examination of the skeleton revealed mildly narrowed hand and knee joint gaps as a result of degenerative changes, and osteoporosis in the joints of the hand, skull, knees and pelvis (Fig. 1). The bone mineral density, as assessed by quantitative ultrasound, was $0.254 \mathrm{~g} / \mathrm{cm}^{2}$ (T-score, -3.2).

Hypercalcemia was considered to be secondary to hyperthyroidism and methimazole therapy (10 mg three times a day) was continued. The patient was also managed with hydration by intravenous infusion of isotonic saline for 3 days, after which time the serum calcium level remained at $3.0 \mathrm{mmol} / \mathrm{l}$ and serum phosphate at $1.25 \mathrm{mmol} / \mathrm{l}$. Therefore, therapy with salmon calcitonin (50 IU once a day) and alendronate (70 mg once a week) was initiated. After 1 week, the serum calcium and phosphate levels had decreased to 2.71 and $1.26 \mathrm{mmol} / \mathrm{l}$, respectively, and were normalized to 2.44 and $1.19 \mathrm{mmol} / \mathrm{l}$, respectively, after 2 weeks. The thyroid function tests revealed a TSH level of $0.001 \mu \mathrm{IU} / \mathrm{ml}, \mathrm{T}_{3}$ of $1.87 \mathrm{ng} / \mathrm{ml}$ and a $\mathrm{T}_{4}$ of $13.90 \mu \mathrm{g} / \mathrm{dl}$. The patient's appetite gradually improved and she started to gain weight. Calcitonin was then discontinued, while therapy with methimazole (30 mg/day) and alendronate (70 mg/week) was continued.

Three months after the start of anti-thyroid treatment, the patient had no nausea, vomiting or joint pain and had recovered a normal appetite, with a weight gain of $\sim 10 \mathrm{~kg}$. Euthyroidism was achieved and the serum calcium and phosphate levels returned to normal (2.31 and $1.12 \mathrm{mmol} / \mathrm{l}$, respectively); therefore, the dose of methimazole was reduced $(5 \mathrm{mg}$ three times a day) and alendronate was discontinued. Six months later, the patient's serum calcium and phosphate levels remained 
normal, and her osteocalcin levels had diminished compared with the previously measured level $(80.40 \mathrm{ng} / \mathrm{ml})$.

\section{Discussion}

The most common cause of hypercalcemia in hyperthyroidism is concurrent primary hyperparathyroidism; however, in $15-20 \%$ of the cases, alterations in calcium metabolism are related solely to hyperthyroidism (2). A linear correlation exists between serum calcium levels and the parameters of thyroid function; this effect is more pronounced in the $>60$ age group (4).

Hypercalcemia secondary to hyperthyroidism is non-PTH dependent, with enhanced bone resorption and calcium mobilization proposed as the underlying mechanism. The high circulating levels of interleukin (IL)-6 associated with hyperthyroidism stimulate bone osteoclastic activity and alter osteoblast-osteoclast coupling (5). Furthermore, $\mathrm{T}_{3}$ increases the sensitivity of the bone to IL-6 (6). Elevated serum calcium levels may inhibit antidiuretic hormone and PTH secretion (7), increase urine output and promote calcium and phosphate excretion from the renal tubules by interaction with the calcium-sensing receptors in the loops of Henle (8). Additionally, the intestinal absorption of calcium is reduced as a result of the reduced PTH secretion, as well as thyroid hormone inhibition of 1,25-dihydroxyvitamin D synthesis and interference with vitamin D metabolism.

The incidence of osteoporosis in patients with hyperthyroidism is $\sim 20-50 \%$. Despite a diagnosis of hyperthyroidism, our patient presented with extensive osteoporosis and significantly increased osteocalcin levels, indicative of increased osteoblastic activity and bone formation. Following treatment for hyperthyroidism, the osteocalcin levels were reduced, but remained higher than normal; these observations are consistent with a previous report by Nagasaka et al, who reported that bone resorption occurs in untreated patients with Graves' thyrotoxicosis and is rapidly ameliorated following normalization of thyroid hormone levels. However, the accelerated bone formation persists for at least 4-8 months (9). With regard to the patient described herein, further follow-up is required to determine whether her osteoporosis was secondary to hyperthyroidism or also due to menopause.

Control of hyperthyroidism is the main treatment for hypercalcemia and osteoporosis secondary to hyperthyroidism, with anti-thyroid drug therapy as the first choice. However, in the initial stages, when anti-thyroid treatment has not achieved full efficacy, prompt reduction in serum calcium may be required, particularly if hypercalcemia or other symptoms are severe. In resistant cases, other modalities of treatment, such as calcitonin or diphosphate, may be required in addition to general management with saline hydration or diuretics. However, 131Iodine treatment may lead to the destruction of thyroid follicular cells and increased thyroid hormone release, which may even induce a hypercalcemic crisis; therefore, this treatment should be avoided in hyperthyroid patients with hypercalcemia (10).

The patient in the present case did not exhibit clinical manifestations typical of hyperthyroidism; as a result, she was misdiagnosed with rheumatoid arthritis and osteoarthritis for several years, with poor efficacy of the prescribed treatment. The hypercalcemia was confirmed to be secondary to hyperthyroidism, as supported by the relief of her symptoms and resolution of hypercalcemia with treatment of the underlying thyroid condition. Therefore, clinicians should include hyperthyroidism in the differential diagnosis of persistent arthralgia, even if the patients do not present with the typical symptoms of hyperthyroidism.

\section{References}

1. Reddy PA, Harinarayan CV, Sachan A, Suresh V and Rajagopal G: Bone disease in thyrotoxicosis. Indian J Med Res 135: 277-286, 2012.

2. Baxter JD and Bondy PK: Hypercalcemia of thyrotoxicosis. Ann Intern Med 65: 429-442, 1966.

3. Alikhan Z and Singh A: Hyperthyroidism manifested as hypercalcemia. South Med J 89: 997-998, 1996.

4. Szabó ZS and Ritzl F: Hypercalcemia in hyperthyroidism. Role of age and goiter type. Klin Wochenschr 59: 275-279, 1981.

5. Akalin A, Colak O, Alatas O and Efe B: Bone remodelling markers and serum cytokines in patients with hyperthyroidism. Clin Endocrinol (Oxf) 57: 125-129, 2002.

6. Iqbal AA, Burgess EH, Gallina DL, Nanes MS and Cook CB: Hypercalcemia in hyperthyroidism: Patterns of serum calcium, parathyroid hormone, and 1,25-dihydroxyvitamin D3 levels during management of thyrotoxicosis. Endocr Pract 9: 517-521, 2003.

7. Mosekilde L, Eriksen EF and Charles P: Effects of thyroid hormones on bone and mineral metabolism. Endocrinol Metab Clin North Am 19: 35-63, 1990.

8. Marx SJ, Sharp ME, Krudy A, Rosenblatt M and Mallette LE: Radioimmunoassay for the middle region of human parathyroid hormone: Studies with a radioiodinated synthetic peptide. J Clin Endocrinol Metab 53: 76-84, 1981.

9. Nagasaka S, Sugimoto H, Nakamura T, Kusaka I, Fujisawa G, Sakuma N, Tsuboi Y, Fukuda S, Honda K, Okada K, et al: Antithyroid therapy improves bony manifestations and bone metabolic markers in patients with Graves' thyrotoxicosis. Clin Endocrinol (Oxf) 47: 215-221, 1997.

10. Du W, Cuige L, Liu X, et al: A case of calcium crisis after 131I therapy of Graves' disease. Chin J Integr Med 51: 315-316, 2012. 